\title{
Factorial Validity of the English-Language Version of the Pain Catastrophizing Scale-Child Version
}

\author{
Holly A. Parkerson, * Melanie Noel, ${ }^{\dagger}$ M. Gabrielle Pagé, ${ }^{\ddagger}$ Samantha Fuss, ${ }^{\ddagger}$ Joel Katz, ${ }^{\ddagger}$ \\ and Gordon J. G. Asmundson* \\ *Department of Psychology, University of Regina, Regina, Saskatchewan, Canada. \\ ${ }^{\dagger}$ Center for Child Health, Behavior \& Development, Seattle Children's Research Institute, Seattle, Washington. \\ ¿Department of Psychology, York University, Toronto, Ontario, Canada.
}

\begin{abstract}
The Pain Catastrophizing Scale (PCS) was developed in English to assess 3 components of catastrophizing (rumination, magnification, helplessness). It has been adapted for use and validated with Flemish-speaking children (Pain Catastrophizing Scale for Children [PCS-C]) and French-speaking adolescents. The PCS-C has been back-translated to English and used extensively in research with English-speaking children; however, the factorial validity of the English PCS-C has not been empirically examined. This study assessed the factor structure of the English PCS-C among a community sample of 1,006 English-speaking children (aged 8-18 years). Exploratory factor analysis was conducted using a random subsample $(n=504)$ to assess the underlying factor structure. Items with poor factor loadings were removed. Confirmatory factor analysis, using the second subsample $(n=502)$, was used to cross-validate the factor structure revealed by exploratory factor analysis and compare it to the original 3-factor model and other model variants. Exploratory factor analysis revealed that the original PCS-C and a revised 3-factor model comprising 11 of the original 13 PCS-C items, all loading on their original factors, provided adequate fit to the data. The revised model provided statistically better fit to the data compared to all other model variants, suggesting that the English PCS-C may be better understood using a revised 11 -item oblique 3-factor model.

Perspective: This is the first examination of the factorial validity of the widely used English version of the PCS-C in a large community sample of English-speaking children. A revised 11-item, 3-factor model provided statistically better fit to the data compared to the original model and other model variants.
\end{abstract}

$\mathrm{P}$ ain catastrophizing, defined as an exaggerated negative orientation toward actual or anticipated pain, ${ }^{36}$ is a powerful predictor of pain and disability among adults ${ }^{33}$ and children. ${ }^{1,41}$ It is characterized by

Received January 15, 2013; Revised May 29, 2013; Accepted June 11, 2013. H.A.P. was supported by a Canadian Institutes of Health Research (CIHR) master's award. M.N., M.G.P., and S.F. are trainee members of Pain in Child Health, a Strategic Training Initiative in Health Research of the CIHR. M.G.P. is supported by a Canada graduate scholarship-doctoral award from the CIHR. M.G.P. is a recipient of a Lillian-Wright MaternalChild Health Scholarship from York University and a ClHR Strategic Training Fellow in Pain: Molecules to Community. S.F. is supported by a Canada graduate scholarship-doctoral award from the CIHR and is a CIHR Strategic Training Fellow in Pain: Molecules to Community. J.K. is supported by a CIHR Canada research chair in health psychology grant. Funds to conduct the study were provided by J.K.'s Canada research chair. The authors declare no conflicts of interest.

Address reprint requests to Holly A. Parkerson, MA, Department of Psychology, University of Regina, Regina, Saskatchewan, S4S 0A2, Canada. E-mail: hparkerson@gmail.com recurring cognitions about the magnified threat of pain and its perceived uncontrollable and unmanageable nature, aspects referred to as "rumination," "magnification," and "helplessness." 35 The importance of pain catastrophizing among pediatric populations is reflected in its inclusion in empirically and theoretically derived models proposed to explain the processes through which acute pain becomes exacerbated ${ }^{27}$ and pain transitions to a chronic state during childhood and adolescence. ${ }^{1}$

Consistent with the pediatric fear-avoidance model of chronic pain, ${ }^{1}$ child pain catastrophizing is strongly related to fear of pain ${ }^{18,34}$ and pain-related anxiety. ${ }^{30,31}$ Over and above characteristics of pain, pain catastrophizing predicts pain-related disability among children with recurrent and chronic pain ${ }^{9,21,22}$ and those from community samples. ${ }^{17,41}$ In a recent longitudinal examination of children with functional abdominal pain, pain catastrophizing was used in conjunction with other 
variables to categorize subgroups of children to predict pain trajectories nearly a decade later. Children who initially reported high pain catastophizing, in addition to poorer coping and higher threat perception, negative affect, symptom complaints, and health-related impairment, were more likely to have chronic pain, psychiatric comorbidities, and higher central sensitization in early adulthood. ${ }^{45}$ Pain catastrophizing is thought to make children particularly vulnerable to negative outcomes by evoking, and making them more vulnerable to the effects of, parent behaviors that have been shown to increase child pain. ${ }^{44,46}$ Pain displays of high-catastrophizing children are likely to be poorly read by caregivers ${ }^{42}$ and indiscriminately expressed. ${ }^{43}$ Furthermore, the tendency to catastrophize about pain may impede the child's ability to use and derive benefit from evidence-based interventions to reduce pain and distress. ${ }^{44}$

The Pain Catastrophizing Scale (PCS) was originally developed in English to assess pain catastrophizing in adults. ${ }^{35}$ It has been validated in several languages $^{12,14,23,25,26,47}$ and adapted for use in several age groups, ${ }^{9,38}$ by adults to assess catastrophizing about their significant other's pain, ${ }^{4}$ and by parents to assess catastrophizing about their child's pain. ${ }^{15}$ The PCS was adapted for use with Flemish-speaking children aged 9 to 16 years (Pain Catastrophizing Scale-Child [PCS-C $]^{9}$ ). The content and phrasing of the measure was simplified, and confirmatory factor analysis (CFA) suggested that the original 3-factor model provided good fit to the data, which was invariant across age and gender. The validity of the measure was further supported by its prediction of pain intensity and disability among children with chronic and recurrent pain. Although the PCS-C is a widely used measure of pain catastophizing, exploratory factor analysis (EFA) has never been conducted on the PCS-C with children. Given underlying differences in child and adult nociceptive pain processing, ${ }^{24}$ cognitive processing, and the construct of pain catastrophizing across the life span, ${ }^{11}$ the aim of the present study was to assess the factor structure of the PCS-C using EFA and CFA in a large community sample of children and adolescents.

\section{Methods}

\section{Participants}

The present study was approved by the Research Ethics Board of York University (Toronto, Ontario) and the research division of the Ontario Science Centre in Toronto.

A total of 1,022 participants (ages 8-18, mean $\left[\mathrm{M}_{\mathrm{age}}\right]=11.6$, standard deviation $\left.[S D]=2.7\right)$ were recruited from the Ontario Science Centre during a 4-week period in the summer of 2009 (see ${ }^{13}$ for full recruitment strategy) to participate in this questionnaire-based study. Informed consent and assent were obtained from each parent or guardian and child, respectively, before beginning the study. Data were excluded for 12 participants who withdrew before completion. Data from 4 additional participants were excluded because of obvious inaccuracies (eg, age input as 52 years). The final sample comprised 1,006 participants (54.2\% female). Racial demographics were $60.1 \%$ Caucasian, 7.3\% East Asian, 6.6\% South Asian, 4.8\% African Canadian, 4.0\% African Caribbean, 2.7\% Middle Eastern, 2.5\% Hispanic/Latino, .7\% Aboriginal, and $10 \%$ of participants identified as "other." In terms of pain frequency, $5.9 \%$ of participants reported experiencing pain every day, $19 \%$ reported experiencing pain once or twice per week, $27.5 \%$ reported have pain once or twice per month, and $18.5 \%$ reported having no pain. Further, $26.6 \%$ of participants reported experiencing pain that lasted 3 months or longer. Significant age differences in pain frequency were not observed for boys or girls. A significantly greater number of older boys (12-18years) reported having experienced persistent pain than younger boys (8-11 years). No such age differences were found for girls.

The random sampling function in SPSS (SPSS Inc, Chicago, IL) was used to randomly divide the entire sample into 2 groups in preparation for factor analyses. Group A, comprising 504 participants (263 girls aged 8-18 years, $M_{\text {age }}=11.72, S D=2.65$ ), was used for preliminary factor testing and item refinement. Group B, comprising 502 participants (282 girls, aged 8-18 years, $\mathrm{M}_{\text {age }}=11.49, \mathrm{SD}=2.60$ ), provided an independent sample for confirming proposed factor structures.

\section{Measures}

The PCS- $\mathrm{C}^{9}$ is a 13 -item self-report measure designed to assess the extent to which children and adolescents experience catastrophic thoughts and feelings when in pain. The measure was adapted from the adult PCS ${ }^{35}$ for use with Flemish-speaking children and adolescents. CFA indicated that like the original PCS, the PCS-C assesses 3 dimensions of catastrophizing about pain: rumination (eg, "I can't keep it out of my mind"), magnification (eg, "I become afraid that the pain will get worse"), and helplessness (eg, "It's awful and I feel that it takes over me"). Items are responded to on a 5-point scale ranging from 0 (not at all) to 4 (extremely). The PCS-C has demonstrated good reliability (total scale $\alpha=.87$, rumination $\alpha=.73$, magnification $\alpha=.68$, helplessness $\alpha=.79$ ), predictive validity, and invariance across age and sex among Flemish-speaking children and adolescents. ${ }^{9}$

\section{Data Analytic Plan}

As noted above, the entire sample was randomly divided into Groups A and B. Data from Group A were used to conduct EFAs of 1-, 2-, and 3-factor models $9,28,35,40$ using principal axis factoring with promax rotation using the "kappa equals 4 default." As the current data were nonnormally distributed, principal axis factoring was deemed to be most appropriate for the current investigation. ${ }^{7}$ Data from Group B were used in CFAs comparing results of the EFAs and the original 3-factor model.

\section{Results}

\section{Descriptive Data}

The PCS-C item means and standard deviations for each group are presented in Table 1. Many of the indices 
Table 1. PCS-C Descriptive Statistics

\begin{tabular}{|c|c|c|c|c|c|c|c|c|c|c|c|}
\hline \multirow[b]{2}{*}{ ITEM No. } & \multicolumn{5}{|c|}{ GROUP $A(N=504)$} & \multirow[b]{2}{*}{ ITEM No. } & \multicolumn{5}{|c|}{ GROUP B $(N=502)$} \\
\hline & MEAN & RANGE & $S D$ & SKEW & KURTOSIS & & MEAN & RANGE & $S D$ & SKEW & KURTOSIS \\
\hline 1 & 1.00 & $0-4$ & .971 & 1.139 & 1.346 & 1 & 1.04 & $0-4$ & 1.047 & 1.170 & 1.171 \\
\hline 2 & 1.03 & $0-4$ & 1.067 & .964 & .400 & 2 & 1.06 & $0-4$ & 1.090 & 1.083 & .626 \\
\hline 3 & .71 & $0-4$ & .951 & 1.437 & 1.748 & 3 & .73 & $0-4$ & 1.037 & 1.573 & 1.945 \\
\hline 4 & 1.02 & $0-4$ & 1.138 & 1.033 & .306 & 4 & 1.01 & $0-4$ & 1.140 & 1.173 & .694 \\
\hline 5 & 1.27 & $0-4$ & 1.238 & .864 & -.173 & 5 & 1.33 & $0-4$ & 1.203 & .770 & -.261 \\
\hline 6 & 1.26 & $0-4$ & 1.149 & .766 & -.167 & 6 & 1.36 & $0-4$ & 1.157 & .701 & -.216 \\
\hline 7 & 1.00 & $0-4$ & 1.231 & 1.055 & .010 & 7 & 1.00 & $0-4$ & 1.219 & 1.131 & .257 \\
\hline 8 & 2.88 & $0-4$ & 1.341 & -.793 & -.741 & 8 & 2.97 & $0-4$ & 1.312 & -.983 & -.323 \\
\hline 9 & 1.73 & $0-4$ & 1.327 & .338 & -.998 & 9 & 1.71 & $0-4$ & 1.279 & .495 & -.850 \\
\hline 10 & 1.68 & $0-4$ & 1.281 & .453 & -.849 & 10 & 1.65 & $0-4$ & 1.243 & .451 & -.806 \\
\hline 11 & 2.04 & $0-4$ & 1.374 & .093 & -1.232 & 11 & 2.09 & $0-4$ & 1.364 & .062 & -1.265 \\
\hline 12 & 1.27 & $0-4$ & 1.215 & .746 & -.315 & 12 & 1.28 & $0-4$ & 1.204 & .804 & -.171 \\
\hline 13 & 1.23 & $0-4$ & 1.185 & .906 & .052 & 13 & 1.30 & $0-4$ & 1.180 & .748 & -.187 \\
\hline PCS-C Total & 16.85 & $0-47$ & 9.617 & .610 & .007 & PCS-C Total & 17.20 & $0-47$ & 9.618 & .728 & .390 \\
\hline
\end{tabular}

of univariate skewness and kurtosis had nonnormal positive distributions, which was an anticipated function of assessing pain catastrophizing in a child sample. ${ }^{11}$ Only 1 variable had significant negative skew (item 8: "I want the pain to go away"). As a single negatively skewed variable among a group of positively skewed variables has the potential to degrade EFA solutions, ${ }^{37}$ EFAs and CFAs were run with and without item 8 . The following results pertain to analyses that included responses for item 8 , though results of analyses with item 8 yielded similar results. There were no significant differences between groups in PCS-C total scores, $\mathrm{t}(1006)=.571$, $P=.57, r^{2}<.001$ (PCS-total scores without item 8, $\left.\mathrm{t}(1006)=-.427, P=.67, \mathrm{r}^{2}<.001\right)$. The 2 groups were not significantly different with regard to age, $\mathrm{t}(504)=1.39, P=.164, \mathrm{r}^{2}<.001$. Correlations between age and PCS-C total score were nonsignificant for Group $A, r(504)=-.015, P<.37$ nor Group $B, r(502)=-.021$, $P<.32$; consequently, age was not considered in further analyses. The 2 groups were not significantly different with regard to sex, $\chi^{2}(1)=1.615, P=.204$. However, significant differences were found within each group, suggesting that girls had higher levels of catastrophizing: (Group $\mathrm{A}, \mathrm{t}(504)=3.64, P<.001, \mathrm{r}^{2}=.16$; Group $\mathrm{B}$, $\left.t(502)=3.68, P<.001, r^{2}=.16\right)$. Although effect sizes were small and this finding is not uncommon for painrelated ${ }^{8,5}$ and anxiety ${ }^{13}$ measures, CFAs of the model with the best goodness of fit were conducted separately for females and males in order to assess whether the model would vary as a function of sex.

\section{EFAs and Item Reduction}

Principal axis factoring was conducted on the 13 items with promax rotation. Scree plot and eigenvalues $>1$ suggested retention of 2 factors, whereas parallel analysis suggested retention of 1 factor. $^{32}$ Because 3-factor solutions have been previously identified in adult ${ }^{35}$ and child $^{9}$ samples, the current investigation extracted $1-, 2-$, and 3-factor solutions with and without PCS-C item 8 included. One-factor solutions revealed a unitary catastrophizing construct with all items loading $\geq .45$ (with item 8) and $\geq .56$ (without item 8), accounting for $42 \%$ and $44 \%$ of the variance, respectively. Two-factor solutions had 3 items (items 7,12 , and 13) that loaded poorly on all factors $(<.4),{ }^{37}$ which were removed from the analyses. Remaining item loadings were $\geq .52$ (with item 8) and $\geq .62$ (without item 8), accounting for $52 \%$ and $55 \%$ of the variance, respectively. The 3 -factor solution revealed 1 dominant factor (composed of 9 items) and 2 smaller factors (each composed of only 2 items). Removal of item 8 resulted in a solution with a more even distribution of items across factors $(5,3$, and 3 items, respectively). Item 12 ("There is nothing I can do to stop the pain") was also removed from the analyses, as it loaded poorly (ie, $\leq .26$ ) on all factors. The revised 3 -factor model accounted for $54 \%$ of the variance (helplessness $=46 \%$, rumination $=6 \%$, magnification $=2 \%$ ). Item loadings from the pattern matrix of the revised 3-factor solution are presented in Table 2.

\section{CFAs}

CFA was used to evaluate the aforementioned models, as well as the original 3-factor model proposed by Crombez and colleagues. ${ }^{9}$ Three-factor solutions were evaluated using oblique and second-order factor structures. All CFAs were conducted using AMOS 20 (SPSS Inc) with data from Group B. Model fit was assessed using $\chi^{2}$ (values should not be significant), $\chi^{2} / \mathrm{df}$ (values should be $<2.0$ ), the comparative fit index (values should be $>$.95), the root mean square error of approximation (values should be <.06), expected cross-validation index (ECVI; smaller values are a better fit), and the standardized root mean square residual (values should be $<.08){ }^{3,16}$ Emphasis should be placed on the last $5 \mathrm{fit}$ indices when evaluating goodness of fit, as $\chi^{2}$ indices have a potential for inflation associated with sample size. ${ }^{16}$ Fit indices for the models are presented in Table 3. Only the original and revised 3-factor oblique models from the EFAs provided adequate fit to the data. A traditional nested $\chi^{2}$ difference test revealed a 
Table 2. Pattern Matrix of the Revised 3-Factor Pain Catastrophizing Scale-Child

\begin{tabular}{|c|c|c|c|c|}
\hline \multirow[b]{2}{*}{ ITEM No. } & \multirow[b]{2}{*}{ GROUP $B(N=502)$} & \multicolumn{3}{|c|}{ FACTOR } \\
\hline & & 1 & 2 & 3 \\
\hline 2 & $\begin{array}{l}\text { I feel I can't go on like this much } \\
\text { longer }\end{array}$ & .850 & -.019 & -.155 \\
\hline 3 & $\begin{array}{l}\text { It's terrible and I think it's never } \\
\text { going to get better }\end{array}$ & .687 & -.012 & .012 \\
\hline 1 & $\begin{array}{l}\text { I worry all the time whether the } \\
\text { pain will go away }\end{array}$ & .616 & .036 & .174 \\
\hline 4 & $\begin{array}{l}\text { It's awful and I feel it takes } \\
\text { over me }\end{array}$ & .589 & -.073 & .155 \\
\hline 5 & I can't stand it anymore & .575 & -.061 & .158 \\
\hline 10 & $\begin{array}{l}\text { I keep thinking about how much } \\
\text { it hurts }\end{array}$ & -.066 & -.916 & .033 \\
\hline 9 & I can't keep it out of my mind & .079 & -.782 & -.096 \\
\hline 11 & $\begin{array}{l}\text { I keep thinking about how much } \\
\text { I want the pain to stop }\end{array}$ & .004 & -.587 & .103 \\
\hline 6 & $\begin{array}{l}\text { I become afraid that the pain will } \\
\text { get worse }\end{array}$ & .281 & -.081 & .516 \\
\hline 13 & $\begin{array}{l}\text { I wonder whether something } \\
\text { serious may happen }\end{array}$ & .096 & -.218 & .433 \\
\hline 7 & $\begin{array}{l}\text { I keep thinking of other painful } \\
\text { events }\end{array}$ & .127 & -.173 & .359 \\
\hline
\end{tabular}

significant difference $(P=.001)$ between these 2 models, indicating that the revised PCS-C provided a statistically better fit to the data than the original model. Results of the ECVI, a comparative fit index, also indicated that the revised PCS-C provided a statistically better fit to the data than the original model (see Table 3). In order to assess whether the revised model varied as a function of sex, CFAs were conducted separately for males and females using the entire sample. Fit indices (available from authors on request) remained similar to those reported above, supporting model invariance across sex.

CFAs of the original and revised PCS-C were also conducted using a subsample of individuals with pain (ie, those experiencing pain at least "once or twice a week"). The pattern of results for the original and revised PCS-C did not change. Results of the ECVI indicated that the revised PCS-C provided a statistically better fit to the data than the original model (see Table 3). A traditional nested $\chi^{2}$ difference test revealed a significant difference $(P<.05)$ between the 2 models, also indicating that the revised PCS-C provided a statistically better fit to the data than the original model in a subsample of individuals with pain.

\section{Internal Consistency}

Data from Group B were used to calculate internal consistency, means, and SDs for the 3 factors of the revised 3factor model. Cronbach's alpha for the subscales were as follows: helplessness, .84 (mean $=5.03, \mathrm{SD}=4.24)$; rumination, .81 (mean $=5.44, S D=3.40)$; and magnification, .71 (mean $=3.49, \mathrm{SD}=2.84$ ). Cronbach's alpha for the revised 3-factor model was .90 (mean $=13.97$, $S D=9.13$ ). As previously suggested, we recommend that the subscale scores on the PCS-C be calculated by summing items related to each factor. ${ }^{35}$ Factors of the revised PCS-C are composed of the following items: rumination $=9,10,11$; helplessness $=1,2,3,4,5$; and magnification $=6,7,13$.

\section{Discussion}

The primary purpose of this study was to provide the first empirical investigation of the factor structure of the PCS-C in a large English-speaking community sample. The EFAs provided acceptable 1-, 2-, and 3-factor solutions. The CFAs indicated that both the original PCS-C and a revised 3-factor solution comprising 11 of the original 13 items provided an adequate fit to data; however, the revised PCS-C provided a statistically significantly better fit when compared with the original PCS-C model and the other model variants suggested by EFAs. All items of the revised 3-factor model loaded on their original factors and, therefore, support previous research indicating that the PCS and PCS-C assess 3 related yet distinct dimensions of catastrophizing (rumination, magnification, helplessness) in adult ${ }^{35}$ and child samples. ${ }^{9}$ Total and subscale scores of the revised 3-factor model demonstrated good

Table 3. Results of CFAs

GROUP B $(N=502)$

\begin{tabular}{|c|c|c|c|c|c|c|c|}
\hline MODEL & $\chi^{2 / D F}$ & CFI & RMSEA & RMSEA CI & $E C V I$ & $\mathrm{ECVICI}$ & SRMR \\
\hline Original 3-factor (second order) & $230 / 63$ & .938 & .073 & $.063-.083$ & 571 & $.486-.672$ & .0916 \\
\hline Original 3-factor (oblique) & $169 / 62$ & .96 & .059 & $.048-.070$ & .455 & $.385-.540$ & .0366 \\
\hline 1-factor (with item 8) & $380 / 65$ & .883 & .098 & $.089-.108$ & .862 & $.747-.992$ & .0555 \\
\hline 1-factor (without item 8) & $317 / 54$ & .896 & .099 & $.088-.109$ & .728 & $.623-.847$ & .0524 \\
\hline 2-factor (with item 8) & $258 / 64$ & .928 & .078 & $.068-.088$ & .622 & $.531-.728$ & .0506 \\
\hline 2-factor (without item 8) & $212 / 53$ & .937 & .077 & $.067-.088$ & .523 & $.441-.620$ & .0495 \\
\hline Revised 3-factor (second order) & $142 / 43$ & .955 & .068 & $.056-.081$ & .377 & $.312-.457$ & .0456 \\
\hline Revised 3-factor (oblique) & $94 / 41$ & .978 & .051 & $.037-.064$ & .287 & $.238-.351$ & .0297 \\
\hline Pain Sample Original 3-factor (oblique) & $100 / 62$ & .96 & .07 & $.044-.095$ & 1.257 & $1.070-1.506$ & .0508 \\
\hline Pain Sample Revised 3-factor (oblique) & $66 / 41$ & .97 & .07 & $.036-.100$ & .922 & $.776-1.130$ & .0429 \\
\hline
\end{tabular}

Abbreviations: CFI, comparative fit index; RMSEA, root mean square error of approximation; CI, confidence interval; ECVI, expected cross-validation index; SRMR, standardized root mean square residual. 
internal consistency, slightly higher than those reported in examinations of the original PCS (with the exception of the rumination subscale ${ }^{35}$ ) and the PCSC. ${ }^{9}$ Results provide evidence that like the original PCS-C and unlike the PCS, dimensions of pain catastrophizing assessed by the English version of the PCS-C are invariant across age and sex.

The current investigation revealed differences in item loadings between the revised PCS-C, the Flemishlanguage version of the PCS-C, ${ }^{9}$ and the original PCS. ${ }^{35}$ For example, item 12 ("There is nothing I can do to stop the pain") was problematic for the PCS-C in the current sample, as it loaded poorly on all 3 factors of the revised 3-factor solution. Similarly, although item 8 ("I want the pain to go away") had salient loading in all of the solutions, it was subsequently removed from analyses because it demonstrated significant negative skew (ie, it was strongly endorsed by more than half of the participants). This finding seems intuitive, as pain is an evolutionarily relevant and inherently aversive sensory and emotional experience ${ }^{19}$ that typically activates escape tendencies ${ }^{10}$; however, this item was not reported as being problematic in examinations of the factorial structure of the PCS conducted among adults ${ }^{28,29,35}$ nor of the factorial validity of the PCS-C conducted among Flemish-speaking children and adolescents. ${ }^{9}$ Skewness and the degree of individual item endorsement were not reported in these studies; therefore, it is unclear how this item may have affected the respective factor solutions. It is also possible that differences in responses to item 8 found across studies might be related to a change in wording that occurred when the PCS items were adapted for use with children in Flemish (eg, when I am in pain: "I anxiously want the pain to go away" vs "I want the pain to go away") and then back-translated to English. It is recognized that cross-cultural adaptation of self-report tools is a process that should include both linguistic translation as well as adaptation to the culture to maintain content validity of measures across contexts, with back-translation being only one of several steps in this process. $^{2}$ Retention of psychometric properties across translated versions of measures cannot be assumed without formal examination of the validity and reliability of the adapted scale.

Although the present results provide further support for the 3-factor structure of the revised PCS-C, there is emerging evidence to suggest that there may be underlying differences in the construct of pain catastrophizing across the life span. Pediatric pain theorists have recently questioned the developmental appropriateness of the construct in childhood ${ }^{11}$ and argue that unique features of social cognition in youth (eg, magnification of perceived negative consequences, magical thinking, emotional control, fragile coping) make catastrophizing about pain a normal, as opposed to pathologic, developmental process. To support this argument, Eccleston et al ${ }^{11}$ critically examined their own data yielded from 4 studies (mean $=2,348$ ) including children and adolescents from clinical and community samples. The overall mean strength of endorsement for all 13 items of the PCS-C was low (mean $=1.21, \mathrm{SD}=1.08$ ), albeit slightly higher in the clinical sample. This indicates that the cognitions included in the measure were infrequent and relatively weak. Consistent with the present results, they found that item 8 (ie, "When I am in pain, I want it to go away") was the most highly endorsed item and concluded that the PCS-C in its entirety might be more reflective of children's tendency to worry about pain than of their catastrophic beliefs. Furthermore, in contrast to examinations of the adult $\mathrm{PCS}^{35}$ in the present study, the helplessness (vs the rumination) subscale accounted for the largest proportion of variance in the revised PCS-C. Indeed, when compared to adults, children have less experience in emotional coping, fewer problem-solving skills to draw from, and less agency by which to exert control. ${ }^{6,11}$ Such factors could amplify a child's perceived degree of helplessness and contribute to fundamental differences in pain catastrophizing processes in children versus adults. Although a comprehensive understanding of pain during early developmental periods transcends downward extension of knowledge garnered in adulthood and necessitates appreciation of the unique context of childhood, ${ }^{24}$ our assessment tools are often derived from adult constructs and measures; the PCS-C is no exception.

This study had limitations that highlight important avenues for future research. The present study examined a large community sample of children and adolescents. Although recurrent and chronic pediatric pain occurs with high frequency among youth in community samples (eg, median prevalence rates of $11-38 \%{ }^{20}$ ), examination of the factorial validity of the measure in clinical samples of children with chronic pain is warranted. Similarly, given the central role of pain catastrophizing in recently proposed pediatric models to explain factors underlying the exacerbation of acute pain ${ }^{27}$ and the development of chronic pain among children and adolescents, ${ }^{1}$ research should examine the PCS-C among children undergoing invasive painful medical procedures (eg, major surgeries). This would enable examination of its role and sensitivity to change as pain resolves and/or becomes persistent and chronic over time. Despite emerging evidence supporting the powerful role of child pain catastrophizing in predicting trajectories of risk and resilience for chronic pain and psychiatric comorbidities in early adulthood, ${ }^{45}$ it is currently unclear whether pain catastrophizing is a modifiable factor that can be targeted and changed following intervention. Future research should examine the sensitivity of the PCS-C to change through assessment of the construct in clinical samples of children and adolescents before, during, and after they receive evidence-based intervention. However, psychological strategies that have been shown to reduce acute pain and distress among children and adolescents (eg, distraction ${ }^{39}$ ) have been found to be ineffective and may actually intensify the pain experience of highcatastrophizing children during experimental pain. ${ }^{44}$ As such, the unique needs of this vulnerable group of youth should be considered when designing studies that aim to examine the sensitivity of the PCS-C to change, as interventions tailored to their unique needs may first need to be designed. Finally, the structure of the revised 
English-language version of the PCS-C was found to be invariant across age and sex; however, similar to previous research using the Flemish and English-language versions of the PCS-C, ${ }^{9,13}$ girls were found to have higher rates of pain catastrophizing than boys. Differences in the degree to which items are endorsed by girls and boys is deserving of further investigation.

The field of pediatric pain has largely neglected to examine the differential utility and factor structure of its measures, including the PCS-C, separately for children and adolescents; rather, these diverse developmental stages are typically treated as one seemingly homogenous group (eg, 8-18-year-olds). This categorization is likely erroneous because of the rapid and continual changes that occur from early childhood to emerging adulthood in the realms of cognitive and social development, autonomy, and coping skills. ${ }^{6,11}$ As such, the present findings should be interpreted within a developmental context, and future research should examine the validity of the PCS-C across various stages of childhood and adolescence.

To summarize, the present study is the first to provide empirical support for the factorial validity of the

\section{References}

1. Asmundson GJG, Noel M, Petter M, Parkerson H: Pediatric fear-avoidance model of chronic pain: Foundation, application, and future directions. Pain Res Manag 17:397-405, 2012

2. Beaton DE, Bombardier C, Guillemin F, Ferraz MB: Guidelines for the process of cross-cultural adaptation of selfreport measures. Spine 25:3186-3191, 2000

3. Browne MW, Cudeck R: Alternative ways of assessing model fit, in Bollen KA, Long JS (eds): Testing Structural Equation Models. Newbury Park, CA, Sage, 1993, pp 136-162

4. Cano A, Leonard MT, Franz A: The significant other version of the Pain Catastrophizing Scale (PCS-S): Preliminary validation. Pain 19:26-37, 2005

5. Carleton RN, Asmundson GJG, Taylor S: Fear of physical harm: Factor structure and psychometric properties of the Illness/Injury Sensitivity Index. J Psychopathol Behav Assess 27:235-241, 2005

6. Compas BE: Coping with stress during childhood and adolescence. Psychol Bull 101:393-403, 1987

7. Costello $A B$, Osborne JW: Best practices in exploratory factor analysis: Four recommendations for getting the most from your analysis. Pract Assess Res Eval 10:1-9, 2005

8. Cox BJ, Swinson RP, Parker JDA, Kuch K, Reichman JT: Confirmatory factor analysis of the fear questionnaire in panic disorder with agoraphobia. Psychol Assess 5:235-237, 1993

9. Crombez G, Bijttebier P, Eccleston C, Mascagni T, Mertens G, Goubert L, Verstraeten K: The child version of the Pain Catastrophizing Scale (PSC-C): A preliminary validation. Pain 104:639-646, 2003

10. Eccleston C, Crombez G: Pain demands attention: A cognitive-affective model of the interruptive function of pain. Psychol Bull 125:356-366, 1999
English-language version of the PCS-C. Findings suggest that either the revised 11-item or the original 13-item measure can be used with this population for calculation of subscale scores. Consistent with recent thinking and research in the field of pediatric pain, ${ }^{11}$ researchers and clinicians are urged to examine the pattern of endorsement of all PCS-C items, which may be suggestive of developmental differences in the meaning of the construct and the normative nature of the processes described therein. Caution should be used so as to not pathologize what could be typical cognitive and emotional responses to pain in childhood. Pain catastrophizing has consistently emerged as one of the most powerful predictors of pain response and outcomes across the life span, and inclusion of the construct in pediatric pain research will likely continue to flourish. Because scientific discovery is only as sound as the measures used to assess phenomena, the field requires additional investigations into the psychometric properties of the PCS-C, especially in clinical populations, in conjunction with the creation of new developmentally sensitive psychological measures.

11. Eccleston C, Fisher EA, Vervoort T, Crombez G: Worry and catastrophizing about pain in youth: $A$ reappraisal. Pain 153:1560-1562, 2012

12. Fernandez L, Storheim K, Lochting I, Grotle M: Cross-cultural adaptation and validation of the Norwegian Pain Catastrophizing Scale in patients with low back pain. BMC Musculoskelet Disord 13:1-9, 1999

13. Fuss S, Pagé MG, Katz J: Persistent pain in a communitybased sample of children and adolescents: Sex differences in psychological constructs. Pain Res Manag 16:303-309, 2011

14. Garcia Campayo J, Rodero B, Alda M, Sobradiel N, Montero J, Moreno S: Validation of the Spanish version of the Pain Catastrophizing Scale in fibromyalgia. Med Clin 131:487-492, 2008

15. Goubert L, Eccleston C, Vervoort T, Jordan A, Crombez G: Parental catastrophizing about their child's pain: The parent version of the pain catastrophizing scale. Pain 123:254-263, 2006

16. Hu L, Bentler PM: Fit indices in covariance structure modeling: Sensitivity to underparameterized model misspecification. Psychol Methods 3:424-453, 1999

17. Huguet A, Eccleston C, Miró J, Gauntlett-Gilbert J: Young people making sense of pain: Cognitive appraisal, function, and pain in 8-16 year old children. Eur J Pain 13: 751-759, 2009

18. Huguet A, McGrath PJ, Pardos J: Development and preliminary testing of a scale to assess pain-related fear in children and adolescents. J Pain 12:840-848, 2011

19. Classification of chronic pain: Descriptions of chronic pain syndromes and definitions of pain terms. Prepared by the International Association for the Study of Pain Subcommittee on Taxonomy. Pain Suppl 3:S1-S226, 1994

20. King $S$, Chambers CT, Huguet $A$, MacNevin $R C$, McGrath PJ, Parker L, MacDonald AJ: The epidemiology of chronic pain in children and adolescents revisited: A systematic review. Pain 152:2729-2738, 2011 
21. Langer SL, Romano JM, Levy RL, Walker LS, Whitehead WE: Catastrophizing and parental response to child symptom complaints. Child Health Care 38:169-184, 2009

22. Lynch AM, Kashikar-Zuck S, Goldschneider KR, Jones BA: Psychosocial risks for disability in children with chronic back pain. J Pain 7:244-251, 2006

23. Maric A, Banozic A, Cosic A, Kraljevik S, Sapunar D, Puljak L: Validation of the Croatian Pain Catastrophizing Scale through a study on the influence of medical education on pain catastrophizing. Period Biol 113:171-175, 2011

24. McGrath PA: Children-Not simply "little adults", in Mersky H, Loeser JD, Dubner R (eds): The Paths of Pain. Seattle, WA, IASP Press, 2005, pp 1975-2005

25. Meyer K, Sprott H, Mannion AF: Cross-cultural adaptation, reliability, and validity of the German version of the Pain Catastrophizing Scale. J Psychosom Res 64:469-478, 2008

26. Miro J, Nieto R, Huguet A: The Catalan version of the Pain Catastrophizing Scale: A useful instrument to assess catastrophic thinking in whiplash patients. Pain 9:397-406, 2008

27. Noel M, Chambers CT, Petter M, McGrath PJ, Klein RM, Stewart SH: "Pain is not over when the needle ends": A review and preliminary model of acute pain memory development in childhood. Pain Manag 2:487-497, 2012

28. Osman A, Barrios FX, Gutierrez PM, Kopper BA, Merrifield T, Grittman L: The Pain Catastrophizing Scale: Further psychometric evaluation with adult samples. J Behav Med 23:351-365, 2000

29. Osman A, Barrios FX, Kopper BA, Hauptmann W, Jones J, O'Neill E: Factor structure, reliability, and validity of the Pain Catastrophizing Scale. J Behav Med 10:263-276, 1997

30. Pagé MG, Campbell F, Isaac L, Stinson J, MartinPichora AL, Katz J: Reliability and validity of the Child Pain Anxiety Symptoms Scale (CPASS) in a clinical sample of children and adolescents with acute postsurgical pain. Pain 152: 1958-1965, 2011

31. Pagé MG, Fuss S, Martin AL, Escobar EMR, Katz J: Development and preliminary validation of the Child Pain Anxiety Symptoms Scale in a community sample. J Pediatr Psychol 35: 1071-1082, 2010

32. Patil VH, Singh SN, Mishra S, Donovan T: Efficient theory development and factor retention criteria: Abandon the "eigenvalue greater than one" criterion. J Business Res 61: 162-170, 2008

33. Severeijns R, Vlaeyen JWS, van den Hout MA, Weber WEJ: Pain catastrophizing predicts pain intensity, disability, and psychological distress independent of the level of physical impairment. Clin J Pain 17:165-172, 2001

34. Simons LE, Kaczynski KJ: The fear avoidance model of chronic pain: Examination for pediatric application. J Pain 13:827-835, 2012
35. Sullivan MJL, Bishop SR, Pivik J: The Pain Catastrophizing Scale: Development and validation. Psychol Assess 7: 524-532, 1995

36. Sullivan MJL, Thorn B, Haythornthwaite JA, Keefe F, Martin M, Bradley LA, Lefebvre JC: Theoretical perspectives on the relation between catastrophizing and pain. Clin J Pain 17:52-64, 2001

37. Tabachnick BG, Fidell LS: Using Multivariate Statistics, 6th ed. Boston, Allyn \& Bacon, 2013

38. Tremblay I, Beaulieu Y, Bernier A, Crombez G, Laliberté $S$, Thibault $P$, Velly AM, Sullivan MJL: Pain catastrophizing scale for francophone adolescents: A preliminary validation. Pain Res Manag 13:19-24, 2008

39. Uman LS, Chambers CT, McGrath PJ, Kisely S: Psychological interventions for needle-related procedural pain and distress in children and adolescents (review). Cochrane Database Syst Rev;CD0051779, 2006

40. Van Damme S, Crombez G, Bijttebier P, Goubert L, Van Houdenhove B: A confirmatory factor analysis of the Pain Catastrophizing Scale: Invariant factor structure across clinical and non-clinical populations. Pain 96:319-324, 2002

41. Vervoort T, Eccleston C, Goubert L, Buysse A, Crombez G: Children's catastrophic thinking about their pain predicts pain and disability 6 months later. Eur J Pain 14:90-96, 2010

42. Vervoort T, Goubert T, Crombez G: The relationship between high catastrophizing children's facial display of pain and parental judgment of their child's pain. Pain 142: 142-148, 2009

43. Vervoort T, Goubert L, Eccleston C, Verhoeven K, De Clercq A, Buysse A, Crombez G: The effects of parental presence upon the facial expression of pain: The moderating role of child pain catastrophizing. Pain 138:277-285, 2008

44. Verhoeven K, Goubert L, Jaaniste T, Van Ryckeghem DML, Crombez G: Pain catastrophizing influences the use and the effectiveness of distraction in schoolchildren. Eur J Pain 16 : 256-267, 2011

45. Walker LS, Sherman AL, Bruehl S, Garber J, Smith CA: Functional abdominal pain patient subtypes in childhood predict functional gastrointestinal disorders with chronic pain and psychiatric comorbidities in adolescence and adulthood. Pain 153:1798-1806, 2012

46. Williams SE, Blount RL, Walker LS: Children's pain threat appraisal and catastrophizing moderate the impact of parent verbal behavior on children's symptoms complaints. J Pediatr Psychol 36:55-63, 2011

47. Yap JC, Lau J, Chen PP, Gin T, Wong T, Chan I, Chu J, Wong E: Validation of the Chinese Pain Catastrophizing Scale (HK-PCS) in patients with chronic pain. Pain Med 9: 186-195, 2008 